ARTICLE

\title{
Rationally designed transition metal hydroxide nanosheet arrays on graphene for artificial $\mathrm{CO}_{2}$ reduction
}

Kang-Qiang Lu ${ }^{1,2}$, Yue-Hua Li ${ }^{1,2}$, Fan Zhang ${ }^{1}$, Ming-Yu Qi ${ }^{1,2}$, Xue Chen ${ }^{1,2}$, Zi-Rong Tang ${ }^{1}$, Yoichi M. A. Yamada (1) ${ }^{3}$, Masakazu Anpo ${ }^{1,4}$, Marco Conte (i) ${ }^{5} \&$ Yi-Jun Xu (i) ${ }^{1,2}$

The performance of transition metal hydroxides, as cocatalysts for $\mathrm{CO}_{2}$ photoreduction, is significantly limited by their inherent weaknesses of poor conductivity and stacked structure. Herein, we report the rational assembly of a series of transition metal hydroxides on graphene to act as a cocatalyst ensemble for efficient $\mathrm{CO}_{2}$ photoreduction. In particular, with the Ru-dye as visible light photosensitizer, hierarchical $\mathrm{Ni}(\mathrm{OH})_{2}$ nanosheet arrays-graphene $\left(\mathrm{Ni}(\mathrm{OH})_{2}-\mathrm{GR}\right)$ composites exhibit superior photoactivity and selectivity, which remarkably surpass other counterparts and most of analogous hybrid photocatalyst system. The origin of such superior performance of $\mathrm{Ni}(\mathrm{OH})_{2}-\mathrm{GR}$ is attributed to its appropriate synergy on the enhanced adsorption of $\mathrm{CO}_{2}$, increased active sites for $\mathrm{CO}_{2}$ reduction and improved charge carriers separation/transfer. This work is anticipated to spur rationally designing efficient earth-abundant transition metal hydroxides-based cocatalysts on graphene and other twodimension platforms for artificial reduction of $\mathrm{CO}_{2}$ to solar chemicals and fuels.

\footnotetext{
${ }^{1}$ College of Chemistry, New Campus, Fuzhou University, 350116 Fuzhou, P. R. China. ${ }^{2}$ State Key Laboratory of Photocatalysis on Energy and Environment, College of Chemistry, Fuzhou University, 350116 Fuzhou, P. R. China. ${ }^{3}$ RIKEN Center for Sustainable Resource Science, Hirosawa, Wako, Saitama 351-0198, Japan. ${ }^{4}$ Department of Applied Chemistry, Graduate School of Engineering, Osaka Prefecture University, Osaka 599-8531, Japan. ${ }^{5}$ Department of Chemistry, University of Sheffield, Sheffield S3 7HF, UK. ${ }^{凶}$ email: yjxu@fzu.edu.cn
} 
A rtificial photoreduction of carbon dioxide $\left(\mathrm{CO}_{2}\right)$ into useful chemical feedstocks offers a promising and sustainable long term solution to the issues of increasing energy demands and climate change ${ }^{1-6}$. Nevertheless, there is still a long way to achieve efficient and selective photocatalytic $\mathrm{CO}_{2}$ reduction, especially in diluted $\mathrm{CO}_{2}$, which is primarily because of the low $\mathrm{CO}_{2}$ adsorption, high recombination rate of charge carriers in photocatalysts, concealed active sites, and the competing $\mathrm{H}_{2}$ evolution reaction ${ }^{7-11}$. To overcome these limitations, rational construction of hybrid photocatalytic systems, in which photosensitizers and cocatalysts operate in a harmonious manner, has arisen as a promising approach ${ }^{12-16}$.

Recently, the earth-abundant transition metal hydroxides, especially $\mathrm{Ni}(\mathrm{OH})_{2}$, as cocatalysts for photocatalytic $\mathrm{CO}_{2}$ reduction, have attracted extensive research interests due to their low cost, easy preparation, and effective adsorption for $\mathrm{CO}_{2}^{2,17}$. However, the charge transfer efficiency of $\mathrm{Ni}(\mathrm{OH})_{2}$ is inferior because of its inherent weakness of poor conductivity, which results in the net efficiency of $\mathrm{Ni}(\mathrm{OH})_{2}$ in improving the photoactivity is often limited ${ }^{18,19}$. An effective way to overcome this disadvantage could be incorporating $\mathrm{Ni}(\mathrm{OH})_{2}$ with electrically conductive graphene $(\mathrm{GR})^{1,20}$. In addition, the two-dimensional (2D) GR nanosheets with a large $\pi$-conjugated structure can further enhance the adsorption of $\mathrm{CO}_{2}$ via interacting with delocalized $\pi$-conjugation binding $\pi_{3}^{4}$ of $\mathrm{CO}_{2}$ molecule ${ }^{21,22}$. Moreover, the large $2 \mathrm{D}$ platform and amenable wet-chemistry processability of GR also benefit the controllable composite structure construction ${ }^{1,23-25}$. In particular, rationally constructing nanoarray gradient structures based on vertical sheets-on-sheets is potentially able to harmoniously exert the synergistic ensemble effects of accelerating separation/transfer of charge carriers and exposing open active sites for the efficient adsorption, activation, and photoreduction of $\mathrm{CO}_{2}{ }^{18,26,27}$.

Herein, we report the facile synthesis of a series of different transition metal hydroxides, including $\mathrm{Ni}(\mathrm{OH})_{2}, \mathrm{Fe}(\mathrm{OH})_{3}, \mathrm{Cu}$ $(\mathrm{OH})_{2}$, and $\mathrm{Co}(\mathrm{OH})_{2}$, onto the $2 \mathrm{D}$ platform of $\mathrm{GR}$ to act as cocatalysts ensemble for $\mathrm{CO}_{2}$ photoreduction to solar fuels. With the Ru-dye as a visible-light photosensitizer, the optimal hierarchical $\mathrm{Ni}(\mathrm{OH})_{2}-10 \% \mathrm{GR}$ nanosheet arrays composite exhibits superior activity and selectivity, achieving a high $\mathrm{CO}$ formation rate of $10725 \mu \mathrm{mol} \mathrm{h}^{-1} \mathrm{~g}^{-1}$ and selectivity of $96 \%$ in pure $\mathrm{CO}_{2}$. More importantly, even in diluted $\mathrm{CO}_{2}\left(10 \% \mathrm{CO}_{2}\right.$, representative $\mathrm{CO}_{2}$ concentration of waste gas from coal-fired power stations) ${ }^{7}$, this $\mathrm{Ni}(\mathrm{OH})_{2}-10 \% \mathrm{GR}$ composite still demonstrates the excellent performance with CO production rate of $7432 \mu \mathrm{mol} \mathrm{h}^{-1} \mathrm{~g}^{-1}$ and high selectivity of $92 \%$, which significantly surpasses other counterparts including bare $\mathrm{Ni}(\mathrm{OH})_{2}, \mathrm{Ni}(\mathrm{OH})_{2}$ nanoparticlesgraphene $\left(\mathrm{Ni}(\mathrm{OH})_{2}\right.$ NPs-GR), $\mathrm{Fe}(\mathrm{OH})_{3}-\mathrm{GR}, \mathrm{Cu}(\mathrm{OH})_{2}-\mathrm{GR}$ and $\mathrm{Co}(\mathrm{OH})_{2}$-GR and outperforms most of analogous hybrid cocatalysts system in literatures. The underlying origin for such superior visible-light photoactivity and selectivity over $\mathrm{Ni}(\mathrm{OH})_{2^{-}}$ $10 \% \mathrm{GR}$ has been credited for its appropriate synergy on the effective adsorption of $\mathrm{CO}_{2}$, enriched active sites for $\mathrm{CO}_{2}$ reduction, and excellent charge carriers separation and transfer. It is hoped that this work would provide instructive guideline for rational design of earth-abundant transition metal hydroxidesbased cocatalysts by harnessing the rich surface chemistry of GR and other 2D materials platforms toward efficient and selective solar light driven $\mathrm{CO}_{2}$ reduction to value-added fuels and chemicals in a sustainable way.

\section{Results}

Synthesis and morphology. As shown in Fig. 1a, the growth of transition metal hydroxides on the GR platform can be obtained via in situ heterogeneous nucleation and subsequent oriented crystal growth in solution phase. After transition metal precursor adding into the graphene oxide (GO) solution, the strong electrostatic interaction between negatively GO (Supplementary Fig. 1 and Supplementary Note 1) and transition metal cations $\left(\mathrm{Ni}^{2+}, \mathrm{Fe}^{3+}, \mathrm{Cu}^{2+}, \mathrm{Co}^{2+}\right)$ leads to a firm adsorption of transition metal cations on the surface of $\mathrm{GO}^{21}$. At the beginning of the growth process, hexamethylenetetramine (HMTA) as a hydrolyzing agent can tardily decompose to liberate $\mathrm{OH}^{-}$ions, and then transition metal cations react with $\mathrm{OH}^{-}$ions to form dense transition metal hydroxides nuclei on the surface of $\mathrm{GO}^{17,28}$. The high density of transition metal hydroxide nuclei conduce to the vertical growth of nanosheets because the steric hindrance from adjacent seeds can hinder the in-plane direction growth ${ }^{29}$. Meanwhile, the GO precursor can also be reduced to GR during the thermal reflux process ${ }^{1,20}$, by which different transition metal hydroxide-GR composites are formed.

Since the $\mathrm{Ni}(\mathrm{OH})_{2}-10 \% \mathrm{GR}$ composite exhibits the optimal photocatalytic performance among the as-obtained transition metal hydroxide-GR composites as shown in the section of $\mathrm{CO}_{2}$ photoreduction, the following discussion will mainly focus on the characterizations of $\mathrm{Ni}(\mathrm{OH})_{2}-10 \% \mathrm{GR}$ composite. As shown in Supplementary Fig. 2 and Supplementary Note 2, the morphological evolution process of $\mathrm{Ni}(\mathrm{OH})_{2}-10 \% \mathrm{GR}$ has been investigated via time-dependent SEM images. It can be seen that GO surface is smooth before the refluxing reaction. As refluxing time increases, $\mathrm{Ni}(\mathrm{OH})_{2}$ gradually nucleates and grows on the GR surface, which makes GR surface become rough, and when the refluxing time is prolonged to $7 \mathrm{~h}, \mathrm{Ni}(\mathrm{OH})_{2}$ nanosheet arrays structure begins to form on the GR surface. After refluxing for $10 \mathrm{~h}$, the surface of GR is covered with homogeneous $\mathrm{Ni}(\mathrm{OH})_{2}$ nanosheet arrays as revealed by the SEM images in Fig. 1b, c. In addition, as shown in Supplementary Fig. 3, the thickness of the $\mathrm{Ni}(\mathrm{OH})_{2}$ layers in $\mathrm{Ni}$ $(\mathrm{OH})_{2}-10 \% \mathrm{GR}$ composite can be found to be ca. $10 \mathrm{~nm}$. Notably, it is pivotal to regulate the amount of GR to achieve such evenly dispersed hiearchical $\mathrm{Ni}(\mathrm{OH})_{2}$ nanosheet arrays on the GR platform because the amount of GR affects the morphology of $\mathrm{Ni}(\mathrm{OH})_{2}-\mathrm{GR}$ hybrids significantly. As shown in Supplementary Fig. 4, when the amount of GR is $1 \mathrm{wt} \%$ or $5 \mathrm{wt} \%$, stacked $\mathrm{Ni}(\mathrm{OH})_{2}$ nanosheet arrays are obtained whereas nanosheet array structures cannot be formed when the amount of GR is $30 \mathrm{wt} \%$ or $50 \mathrm{wt} \%$. In addition, in the absence of $\mathrm{GR}$, the as-obtained blank $\mathrm{Ni}(\mathrm{OH})_{2}$ displays a sphere-like aggregated structure (Supplementary Fig. 5), which is because the nucleus formation and growth of blank $\mathrm{Ni}(\mathrm{OH})_{2}$ lack steric hindrance, thereby leading to an omnidirectional and superimposed assembly ${ }^{23}$.

As shown in Fig. 1d, the hierarchical nanosheet array structure of $\mathrm{Ni}(\mathrm{OH})_{2}-10 \% \mathrm{GR}$ is further confirmed by transmission electron microscopy (TEM) characterization. In addition, as shown in Fig. 1e and Supplementary Fig. 6, because the $\alpha-\mathrm{Ni}(\mathrm{OH})_{2}$ is sensitive to electron-beam irradiation, only high-resolution TEM image of $\mathrm{NiO}$ evolved from the $\alpha-\mathrm{Ni}(\mathrm{OH})_{2}$ has been caught (Supplementary Note 3$)^{30-33}$. Furthermore, elemental mapping images of $\mathrm{Ni}(\mathrm{OH})_{2}-10 \% \mathrm{GR}$ hybrid in Fig. If show the spatial distributions of $\mathrm{C}, \mathrm{O}$, and $\mathrm{Ni}$, indicating the uniform growth of $\mathrm{Ni}$ $(\mathrm{OH})_{2}$ nanosheet arrays on the matrix of GR. Furthermore, to determine the length of $\mathrm{Ni}(\mathrm{OH})_{2}$ nanosheet arrays, atomic force microscopy (AFM) of the $\mathrm{Ni}(\mathrm{OH})_{2}-10 \% \mathrm{GR}$ hybrid has been conducted. As displayed in Fig. $1 \mathrm{~g}$ and Supplementary Fig. 7, the topography of $\mathrm{Ni}(\mathrm{OH})_{2}-10 \% \mathrm{GR}$ composite shows a $2 \mathrm{D}$ lamellar structure with a thickness of $c a .60 \mathrm{~nm}$. Considering the thickness of GR sheet $(0.9 \mathrm{~nm})^{34}$ and the growth of $\mathrm{Ni}(\mathrm{OH})_{2}$ on both sides of $\mathrm{GR}$, the length of $\mathrm{Ni}(\mathrm{OH})_{2}$ nanosheet arrays is deduced to be about $30 \mathrm{~nm}$.

Structure characterization. X-ray diffraction (XRD) was used to characterize the crystal structures of these as-synthesized samples. 
a
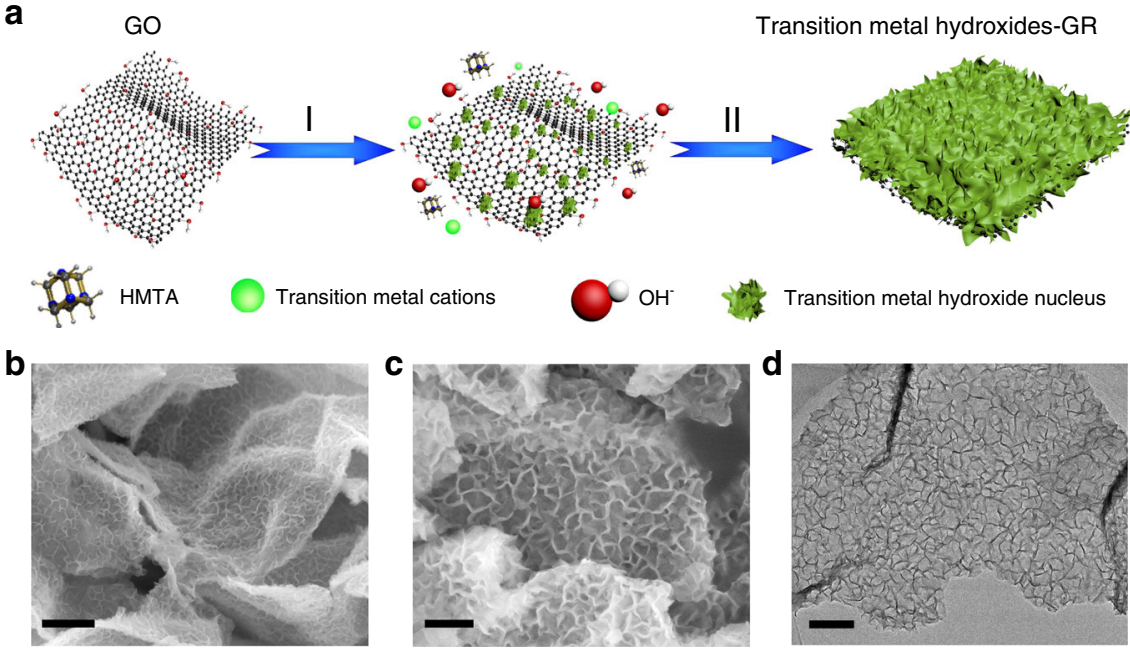

Transition metal hydroxide nucleus
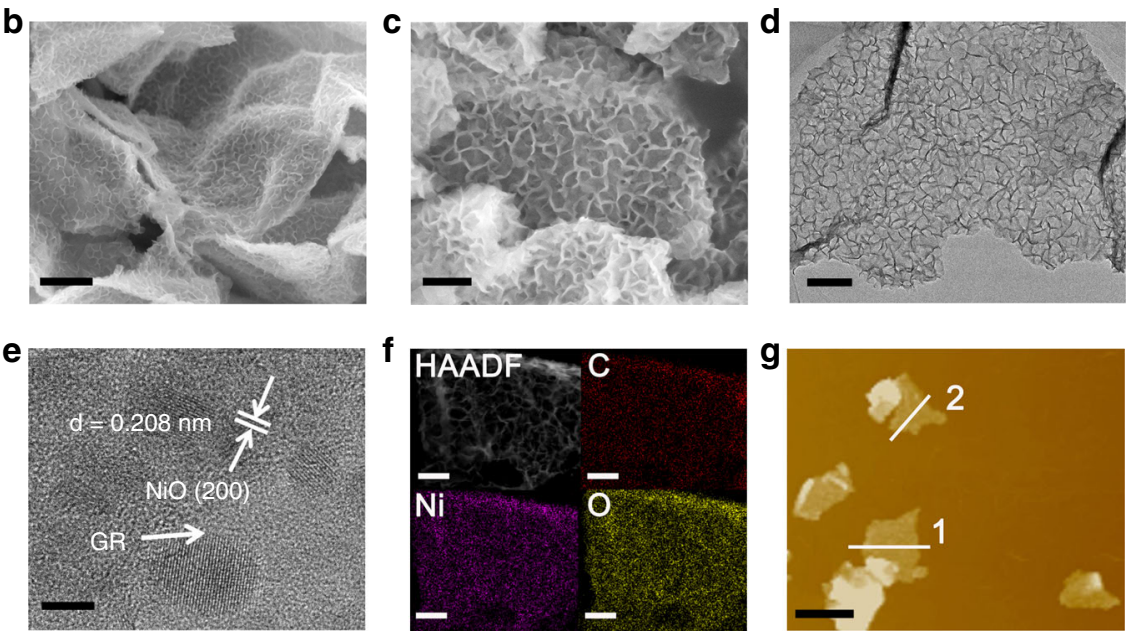

Fig. 1 Synthesis and morphology characterization. a Schematic illustration of synthesis procedure for transition metal hydroxides onto the GR platform. I in situ heterogeneous nucleation, II oriented crystal growth. b, c FESEM images, d TEM image, e HRTEM image, $\mathbf{f}$ elemental mapping results, and $\mathbf{g}$ AFM image of the $\mathrm{Ni}(\mathrm{OH})_{2}-10 \% \mathrm{GR}$. The scale bar are $500 \mathrm{~nm}$ in $\mathbf{b}, 200 \mathrm{~nm}$ in $\mathbf{c}, 100 \mathrm{~nm}$ in $\mathbf{d}, 2 \mathrm{~nm}$ in $\mathbf{e}, 1 \mu \mathrm{m}$ in $\mathbf{f}, 3 \mu \mathrm{m}$ in $\mathbf{g}$.

As shown in Fig. 2a, the diffraction peaks of $\mathrm{Ni}(\mathrm{OH})_{2}$ at $8.7^{\circ}$, $17.3^{\circ}, 33.4^{\circ}$, and $59.9^{\circ}$ can be indexed to (003), (006), (101), and (110) planes of $\alpha-\mathrm{Ni}(\mathrm{OH})_{2}$ (JCPDS no. 38-0715) ${ }^{28,35}$. Two peaks at low angles $\left(<20^{\circ}\right)$ clearly indicate the layered structure of $\mathrm{Ni}$ $(\mathrm{OH})_{2}{ }^{32}$. Notably, the positions of (003) and (006) diffraction peaks shift towards lower angle as compared to that of standard card, indicating enlarged interlayer spacing of as-obtained $\mathrm{Ni}$ $(\mathrm{OH})_{2}$, which has been widely reported in the previous literatures ${ }^{32,36,37}$. In addition, $\mathrm{Ni}(\mathrm{OH})_{2}$-GR hybrids exhibit analogous XRD patterns to that of the blank $\mathrm{Ni}(\mathrm{OH})_{2}$. The diffraction peaks of GR (Supplementary Fig. 8) have not been observed in these composites, which could be because GR layers are densely wrapped by $\mathrm{Ni}(\mathrm{OH})_{2}$ nanosheet arrays ${ }^{18,23}$. The analysis of Raman spectroscopy in Fig. $2 \mathrm{~b}$ shows that peaks at 1353 and $1590 \mathrm{~cm}^{-1}$ are assigned to the D-band and G-band of GR, and the peak at $468 \mathrm{~cm}^{-1}$ is ascribed to $\mathrm{Ni}(\mathrm{OH})_{2}{ }^{28,38}$. The wellidentified $\mathrm{Ni}(\mathrm{OH})_{2}$ and $\mathrm{GR}$ peaks in $\mathrm{Ni}(\mathrm{OH})_{2}-10 \% \mathrm{GR}$ composite indicate that $\mathrm{Ni}(\mathrm{OH})_{2}$ nanosheet arrays have successfully grown on the GR platform. Notably, the $I_{\mathrm{D}} / I_{\mathrm{G}}$ ratio is 0.97 for $\mathrm{Ni}(\mathrm{OH})_{2^{-}}$ $10 \% \mathrm{GR}$, which is lower than 1.01 for GO, indicating that the thermal reduction process enhances the graphitization of $\mathrm{GR}^{34}$. Chemical composition and elemental states of $\mathrm{Ni}(\mathrm{OH})_{2}-10 \% \mathrm{GR}$ composite have been further monitored by X-ray photoelectron spectroscopy (XPS). The survey XPS spectrum in Fig. 2c confirms the existing elements of $\mathrm{C}, \mathrm{Ni}$ and $\mathrm{O}$ in $\mathrm{Ni}(\mathrm{OH})_{2}-10 \% \mathrm{GR}$ composite. In addition, compared with $\mathrm{C} 1 \mathrm{~s}$ spectrum of original GO in Supplementary Fig. 9, the C 1s spectrum of $\mathrm{Ni}(\mathrm{OH})_{2}-10 \%$ GR hybrid shows an obvious loss of oxygenated functional groups, confirming the effective reduction of GO to GR during the thermal reflux process (Fig. 2 d) ${ }^{39,40}$. Furthermore, in the Ni $2 \mathrm{p}$ region of $\mathrm{Ni}(\mathrm{OH})_{2}-10 \% \mathrm{GR}$ composite (Fig. 2e), peaks of $\mathrm{Ni}$ $2 \mathrm{p}_{3 / 2}$ and $\mathrm{Ni} 2 \mathrm{p}_{1 / 2}$ are at 855.9 and $873.5 \mathrm{eV}$, which indicates that the $\mathrm{Ni}$ species are in +2 valence state ${ }^{17,35,41}$. In addition, two shoulder peaks at 861.4 and $879.5 \mathrm{eV}$ are related to the satellite peaks of $\mathrm{Ni} 2 \mathrm{p}_{3 / 2}$ and $\mathrm{Ni} 2 \mathrm{p}_{1 / 2}{ }^{7}$. The $\mathrm{O} 1 \mathrm{~s}$ spectrum in Fig. $2 \mathrm{f}$ displays a typical peak at $531.2 \mathrm{eV}$, which can be ascribed to the $\mathrm{Ni}-\mathrm{OH}$ bond in $\mathrm{Ni}(\mathrm{OH})_{2}-10 \% \mathrm{GR}$ composite ${ }^{18}$. The peak situated at $533.3 \mathrm{eV}$ is assigned to the adsorbed $\mathrm{H}_{2} \mathrm{O}$ molecules ${ }^{30,42}$. Moreover, as shown in Supplementary Fig. 10 and Supplementary Note 4, the thermogravimetric (TG) analysis demonstrates that the actual content of GR in the $\mathrm{Ni}(\mathrm{OH})_{2}-10 \% \mathrm{GR}$ hybrid is ca. $10.3 \mathrm{wt} \%$, which almost equals to the feedstock proportion.

Photoreduction $\mathrm{CO}_{2}$ performance. The visible-light-driven photocatalytic $\mathrm{CO}_{2}$ reduction reactions were performed in a catalytic system with $\left[\mathrm{Ru}(\text { bpy })_{3}\right] \mathrm{Cl}_{2} \cdot 6 \mathrm{H}_{2} \mathrm{O}$ (abbreviated as $\mathrm{Ru}$ ) as photosensitizer and triethanolamine (TEOA) as electron donor. Acetonitrile $(\mathrm{MeCN})$ is selected as a reaction solvent because of its high solubility for $\mathrm{CO}_{2}$. $\mathrm{CO}$ and $\mathrm{H}_{2}$ are detected as the main gas phase products and no liquid phase products (e.g., $\mathrm{HCHO}, \mathrm{CH}_{3} \mathrm{OH}$, and $\mathrm{HCOOH}$ ) are detected (Supplementary Fig. 11 and Supplementary Note 5). As displayed in Fig. 3a, in the presence of Ru alone, low $\mathrm{CO}$ evolution rate $\left(187 \mu \mathrm{mol} \mathrm{h}^{-1} \mathrm{~g}^{-1}\right)$ and selectivity $(67 \%)$ are achieved in pure $\mathrm{CO}_{2}$, which is due to the poor charge transfer efficiency and lack of surface active sites $8,43,44$. The addition of $\mathrm{Ni}$ $(\mathrm{OH})_{2}$ cocatalyst into the $\mathrm{Ru}$ solution leads to a significant improvement of photocatalytic performance. The rate of evolved $\mathrm{CO}$ reaches a value of $4492 \mu \mathrm{mol} \mathrm{h}^{-1} \mathrm{~g}^{-1}$ with $\mathrm{CO}$ selectivity of $87 \%$, which indicates that $\mathrm{Ni}(\mathrm{OH})_{2}$ is an effective cocatalyst for photocatalytic $\mathrm{CO}_{2}$ reduction. Further improvements of photocatalytic activity and selectivity have been achieved after compositing $\mathrm{Ni}(\mathrm{OH})_{2}$ nanosheet arrays with electrically conductive GR. As shown in Supplementary Fig. 12 and Supplementary Note 6, when the content of GR is $10 \%$, the $\mathrm{Ni}(\mathrm{OH})_{2}-10 \% \mathrm{GR}$ composite shows the optimal photocatalytic performance, achieving the $\mathrm{CO}$ formation rate of $10725 \mu \mathrm{mol} \mathrm{h}{ }^{-1} \mathrm{~g}^{-1}$, which is $\sim 2.3$ and 57.2 times as high as that of blank $\mathrm{Ni}(\mathrm{OH})_{2}$ and bare $\mathrm{Ru}$, respectively. The apparent quantum efficiency (AQE) for CO formation at $450 \mathrm{~nm}$ is 

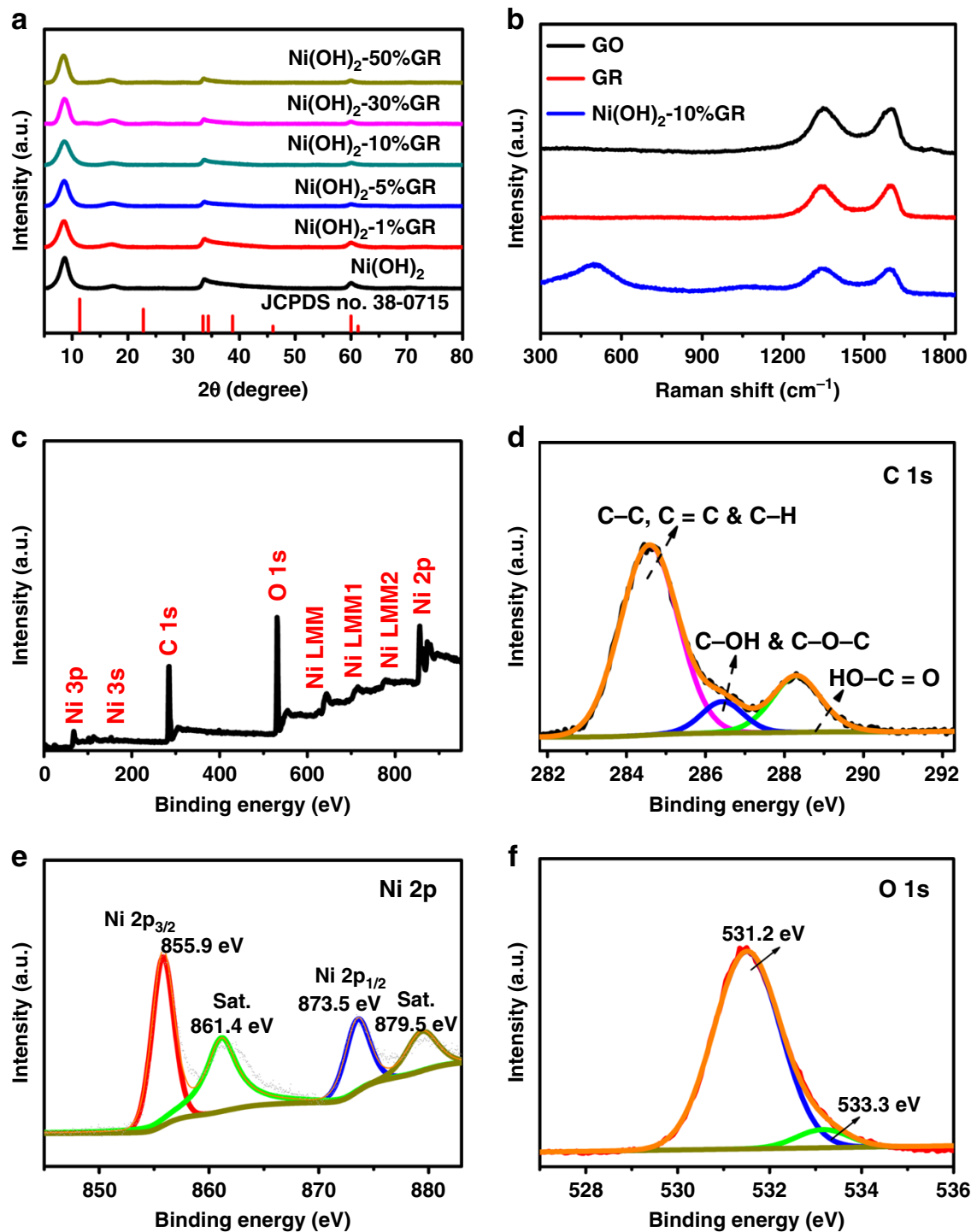

Fig. 2 Structure characterization of $\mathbf{N i}(\mathbf{O H})_{\mathbf{2}}-\mathbf{1 0} \% \mathbf{G R}$. a XRD patterns of $\mathrm{Ni}(\mathrm{OH})_{2}-\mathrm{GR}$ composite with different $\mathrm{GR}$ contents and bare $\mathrm{Ni}(\mathrm{OH})_{2}$. $\mathbf{b}$ Raman spectra of $\mathrm{GO}, \mathrm{GR}$ and $\mathrm{Ni}(\mathrm{OH})_{2}-10 \% \mathrm{GR}$. c XPS survey spectrum, high-resolution XPS spectra of $\mathbf{d} \mathrm{C} 1 \mathrm{~s}$, e $\mathrm{Ni} 2 \mathrm{p}$, and $\mathbf{f} \mathrm{O} 1 \mathrm{~s}$ of $\mathrm{Ni}(\mathrm{OH})_{2}-10 \% \mathrm{GR}$.

calculated to be $1.03 \%$. In addition, the $\mathrm{Ni}(\mathrm{OH})_{2}-10 \% \mathrm{GR}$ hybrid exhibits a superior selectivity of $96 \%$ for photocatalytic $\mathrm{CO}_{2}$ to $\mathrm{CO}$ reduction. Moreover, as shown in Supplementary Table 1, it can be found that the photocatalytic activity and selectivity of $\mathrm{Ni}(\mathrm{OH})_{2}-$ $10 \% \mathrm{GR}$ composite in pure $\mathrm{CO}_{2}$ has exceeded that of most recently reported cocatalysts. Furthermore, $\mathrm{Ni}(\mathrm{OH})_{2}$ nanoparticles-graphene $\left(\mathrm{Ni}(\mathrm{OH})_{2}\right.$ NPs-10\%GR) hybrid has also been synthesized for a comparative study (Supplementary Figs. 13-15 and Supplementary Note 7-9). As demonstrated in Fig. 3a, the $\mathrm{Ni}(\mathrm{OH})_{2} \mathrm{NPs}-10 \% \mathrm{GR}$ composite exhibits lower photocatalytic activity (CO formation rate of $6742 \mu \mathrm{mol} \mathrm{h}^{-1} \mathrm{~g}^{-1}$ ) and CO selectivity (90\%) than that of the $\mathrm{Ni}$ $(\mathrm{OH})_{2}-10 \% \mathrm{GR}$ hybrid, which indicates that constructing hierarchical nanosheet array structure is an effective way to improve photocatalytic performance of the transition metal hydroxide-GR composite.

To assess the practical application of the obtained catalysts, we further perform the $\mathrm{CO}_{2}$ reduction reaction in diluted $\mathrm{CO}_{2}(10 \%$ $\mathrm{CO}_{2}$, representative $\mathrm{CO}_{2}$ concentration of waste gas from coalfired power stations $)^{45}$. As demonstrated in Fig. $3 \mathrm{~b}, \mathrm{Ni}(\mathrm{OH})_{2}-10 \%$ GR composite displays a superior photocatalytic activity with the CO formation rate of $7432 \mu \mathrm{mol} \mathrm{h}^{-1} \mathrm{~g}^{-1}$, corresponding to AQE of $0.95 \%$ at $450 \mathrm{~nm}$. Significantly, $\mathrm{Ni}(\mathrm{OH})_{2}-10 \% \mathrm{GR}$ still exhibits a high $\mathrm{CO}$ selectivity of $92 \%$ in diluted $\mathrm{CO}_{2}$. As shown in Supplementary Table 2, the photocatalytic performance of $\mathrm{Ni}$ $(\mathrm{OH})_{2}-10 \% \mathrm{GR}$ hybrid in diluted $\mathrm{CO}_{2}$ is also superior than that of most previously reported results regarding analogous hybrid photocatalyst system in literatures. In addition, the photocatalytic activity and selectivity of $\mathrm{Ni}(\mathrm{OH})_{2}-10 \% \mathrm{GR}$ hybrid are much higher than that of blank $\mathrm{Ni}(\mathrm{OH})_{2} \quad(\mathrm{CO}$ generation rate of $1717 \mu \mathrm{mol} \mathrm{h}^{-1} \mathrm{~g}^{-1}$ and selectivity of $\left.64 \%\right)$ and $\mathrm{Ni}(\mathrm{OH})_{2} \mathrm{NPs}$ $10 \%$ GR counterpart (CO formation rate of $4890 \mu \mathrm{mol} \mathrm{h}^{-1} \mathrm{~g}^{-1}$ and selectivity of $85 \%$ ) in diluted $\mathrm{CO}_{2}$.

The photocatalytic performance of other transition metal hydroxide-GR $\left(\mathrm{Fe}(\mathrm{OH})_{3}-\mathrm{GR}, \mathrm{Cu}(\mathrm{OH})_{2}-\mathrm{GR}\right.$ and $\left.\mathrm{Co}(\mathrm{OH})_{2}-\mathrm{GR}\right)$ composites have also been tested for comparison under identical reaction conditions (Supplementary Figs. 16-18, Supplementary Notes 10 and 11). Similar to $\mathrm{Ni}(\mathrm{OH})_{2}$-GR composites, $\mathrm{Fe}(\mathrm{OH})_{3^{-}}$ $\mathrm{GR}, \mathrm{Cu}(\mathrm{OH})_{2}-\mathrm{GR}$, and $\mathrm{Co}(\mathrm{OH})_{2}-\mathrm{GR}$ composites also exhibit the optimal photocatalytic performance when the content of GR is 10\%. As displayed in Fig. $3 \mathrm{a}, \mathrm{b}, \mathrm{Ni}(\mathrm{OH})_{2}-10 \% \mathrm{GR}$ or $\mathrm{Ni}(\mathrm{OH})_{2}$ NPs-10\%GR composite shows obviously higher photoactivity and selectivity than that of $\mathrm{Fe}(\mathrm{OH})_{3}-10 \% \mathrm{GR}$ and $\mathrm{Cu}(\mathrm{OH})_{2}-10 \% \mathrm{GR}$ in 
a

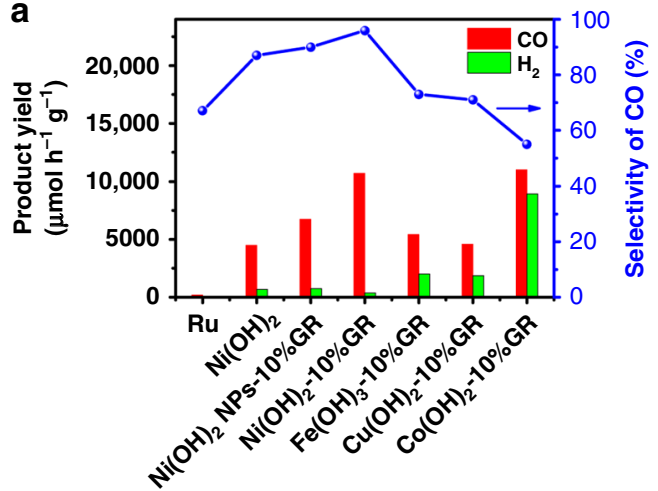

C

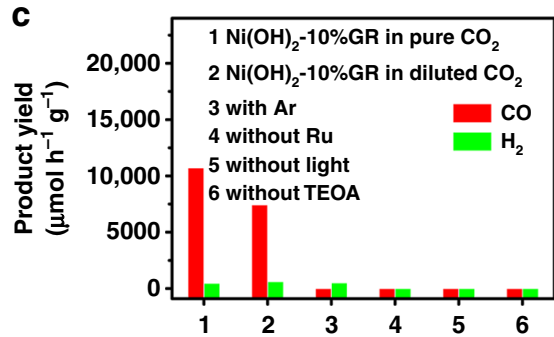

e

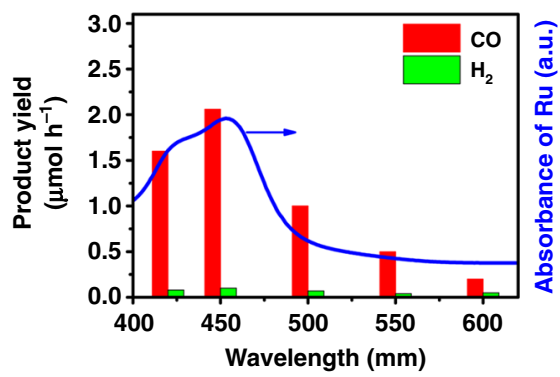

b

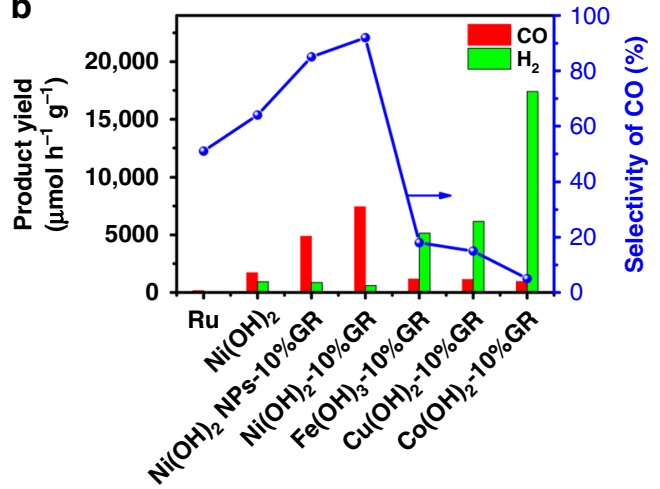

d

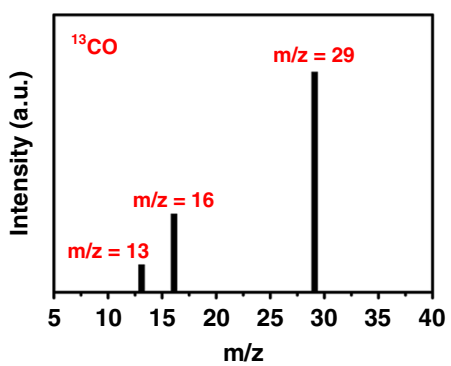

f

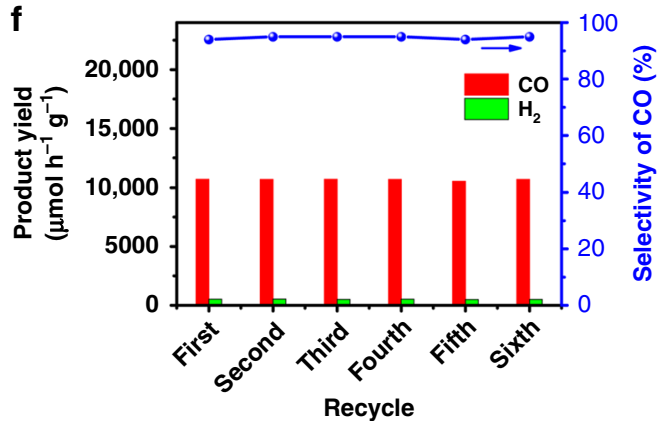

Fig. 3 The photocatalytic performance of $\mathbf{C O}_{\mathbf{2}}$ reduction. $\mathrm{CO}_{2}$ photoreduction performance over $\mathrm{Ru}, \mathrm{Ni}(\mathrm{OH})_{2}, \mathrm{Ni}(\mathrm{OH})_{2} \mathrm{NPs}-10 \% \mathrm{GR}, \mathrm{Ni}(\mathrm{OH})_{2}-10 \% \mathrm{GR}, \mathrm{Fe}$ $(\mathrm{OH})_{3}-10 \% \mathrm{GR}, \mathrm{Cu}(\mathrm{OH})_{2}-10 \% \mathrm{GR}$, and $\mathrm{Co}(\mathrm{OH})_{2}-10 \% \mathrm{GR}$ a in pure $\mathrm{CO}_{2}$ and $\mathbf{b}$ in diluted $\mathrm{CO}_{2} \cdot \mathbf{c} \mathrm{CO}_{2}$ photoreduction performance under various reaction conditions. d Mass spectrum of ${ }^{13} \mathrm{CO}(\mathrm{m} / \mathrm{z}=29)$ produced over $\mathrm{Ni}(\mathrm{OH})_{2}-10 \% \mathrm{GR}$ in the photocatalytic reduction of ${ }^{13} \mathrm{CO}_{2}$. e Wavelength dependence of the yields of $\mathrm{CO}$ and $\mathrm{H}_{2}$ over $\mathrm{Ni}(\mathrm{OH})_{2}-10 \% \mathrm{GR}$, and the light absorption spectrum of the Ru photosensitizer. $\mathbf{f}$ Recycling test of $\mathrm{Ni}(\mathrm{OH})_{2}-10 \% \mathrm{GR}$.

both pure $\mathrm{CO}_{2}$ and diluted $\mathrm{CO}_{2}$. Notably, $\mathrm{Co}(\mathrm{OH})_{2}-10 \% \mathrm{GR}$ shows a CO production rate of $11625 \mu \mathrm{mol} \mathrm{h}^{-1} \mathrm{~g}^{-1}$ in pure $\mathrm{CO}_{2}$, which is slightly higher than that of $\mathrm{Ni}(\mathrm{OH})_{2}-10 \% \mathrm{GR}$. However, the $\mathrm{CO}$ selectivity over $\mathrm{Co}(\mathrm{OH})_{2}-10 \% \mathrm{GR}$ only reaches $56 \%$. Moreover, the $\mathrm{CO}$ formation rate of $\mathrm{Co}(\mathrm{OH})_{2}-10 \% \mathrm{GR}$ dramatically declines to $945 \mu \mathrm{mol} \mathrm{h}^{-1} \mathrm{~g}^{-1}$ with a low CO selectivity of $4 \%$ in diluted $\mathrm{CO}_{2}$. These results clearly demonstrate that $\mathrm{Ni}(\mathrm{OH})_{2}$ is a more efficient and selective cocatalyst for photocatalytic reduction of $\mathrm{CO}_{2}$ to $\mathrm{CO}$ than other transition metal hydroxides.

To further study the factors that could influence the performance of photocatalysts, a series of control experiments are conducted. As displayed in column 3 of Fig. 3c, the comparative reaction in pure argon (Ar) indicates that only slight $\mathrm{H}_{2}$ is produced and no $\mathrm{CO}$ is formed. In addition, isotopic experiment with ${ }^{13} \mathrm{CO}_{2}$ as substrate has also been carried out to confirm the origin of $\mathrm{CO}$. As displayed in Fig. 3d, the mass spectrum signal of ${ }^{13} \mathrm{CO}(\mathrm{m} / \mathrm{z}=29)$ is clearly detected. These results definitely confirm that $\mathrm{CO}$ indeed derives from the photocatalytic reduction of $\mathrm{CO}_{2}{ }^{46}$. In addition, as shown in column 4-6 of Fig. 3c, control experiments in the absence of $\mathrm{Ru}$ or visible-light irradiation or TEOA result in the formation of a trace amount of $\mathrm{CO}$ and $\mathrm{H}_{2}$, which confirms that the $\mathrm{CO}_{2}$ reduction is driven by visible-light irradiation and the sacrificial agent is of great significance. Moreover, as shown in Fig. 3e, the wavelength dependency of CO production shows that the tendency of CO generation matches well with the absorption spectrum of $\mathrm{Ru}$ photosensitizer, further confirming that the photocatalytic $\mathrm{CO}_{2}$ reduction is indeed driven by the absorbed photon of $\mathrm{Ru}^{47}$. Furthermore, the stability of $\mathrm{Ni}(\mathrm{OH})_{2}-10 \% \mathrm{GR}$ cocatalyst has been evaluated by cycle experiments. The result in Fig. $3 \mathrm{f}$ shows that the photoactivity loss over $\mathrm{Ni}(\mathrm{OH})_{2}-10 \% \mathrm{GR}$ composite is negligible after six consecutive cycles. In addition, as shown in Supplementary Figs. 19 and 20, the results of XRD and XPS over fresh and used Ni $(\mathrm{OH})_{2}-10 \% \mathrm{GR}$ show the same crystalline phase structure and element composition. SEM and TEM images of the used $\mathrm{Ni}(\mathrm{OH})_{2-}$ $10 \%$ GR sample in Supplementary Fig. 21 also indicate no obvious structural change after visible light illumination for $12 \mathrm{~h}$. These results clearly demonstrate that $\mathrm{Ni}(\mathrm{OH})_{2}-10 \% \mathrm{GR}$ is a stable cocatalyst for photocatalytic $\mathrm{CO}_{2}$ reduction under present conditions. In addition, the turnover number (TON) for $\mathrm{CO}$ formation respect to $\mathrm{Ru}$ atoms is 4.8 over $5 \mathrm{~h}$ of stable operation, reflecting the catalytic nature of the reaction. Notably, this TON value is higher than that of previously reported ruthenium-nickel molecular photocatalysts ${ }^{48,49}$.

Mechanism of enhanced photocatalytic performance. To reveal the origin of the enhanced photocatalytic performance of $\mathrm{Ni}(\mathrm{OH})_{2}-10 \% \mathrm{GR}$ composite compared to that of other 

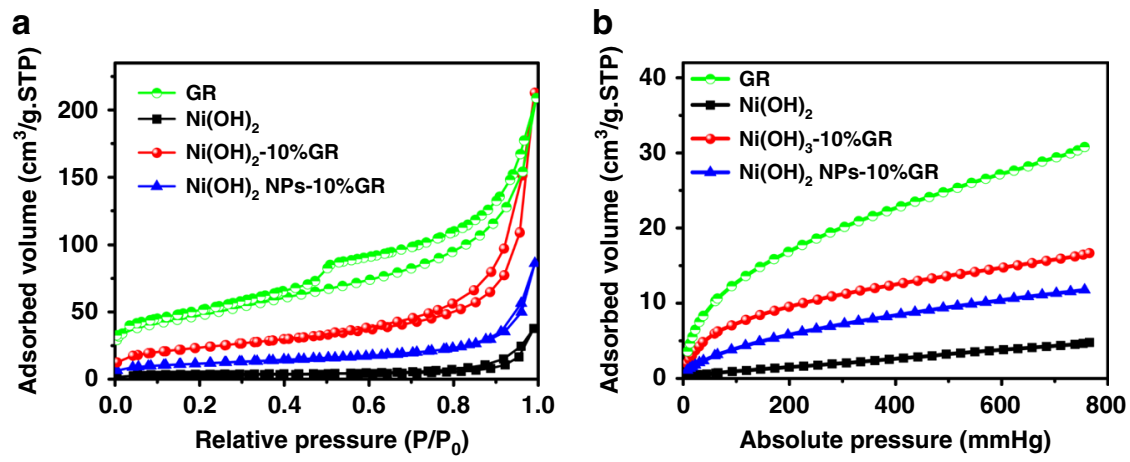

C

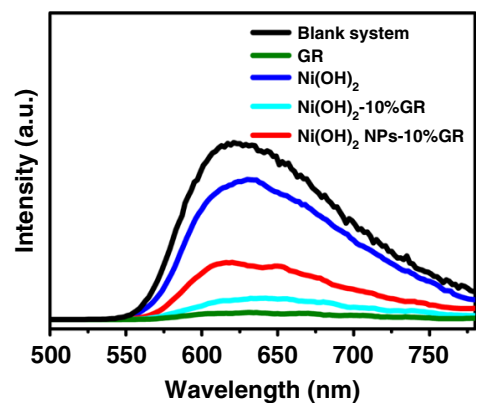

d
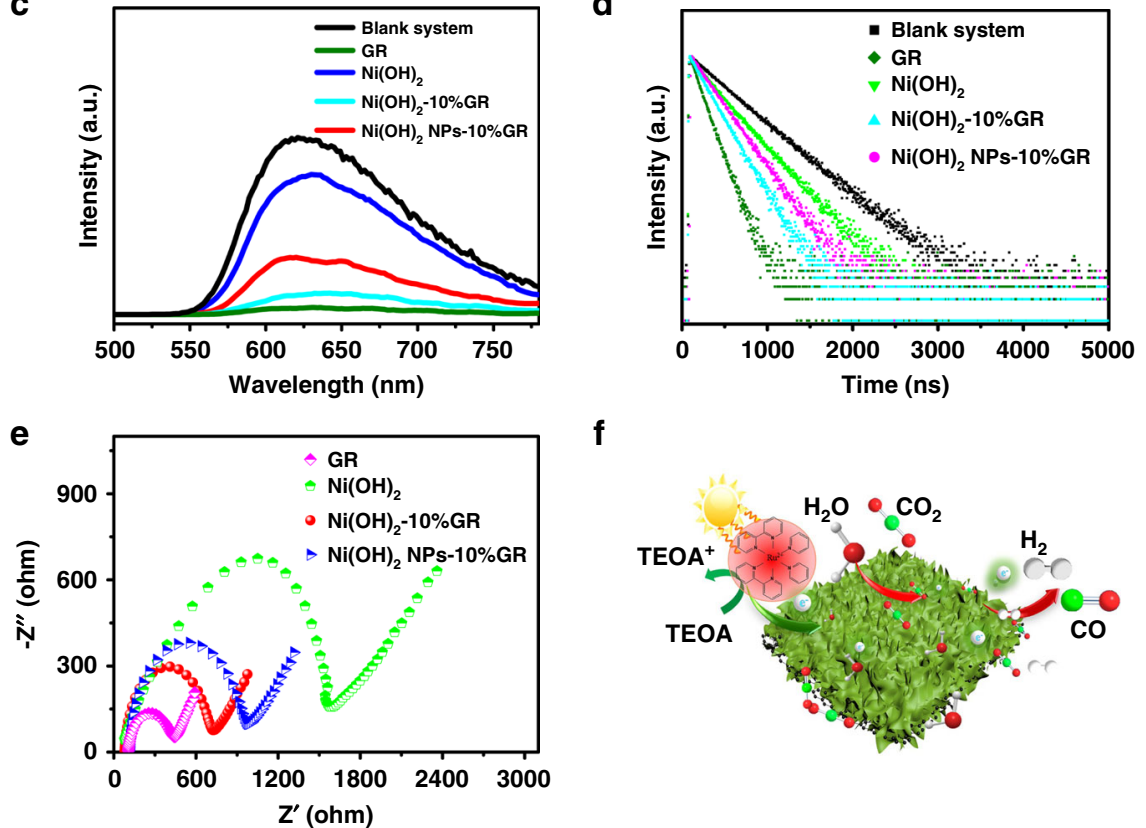

$\mathbf{f}$

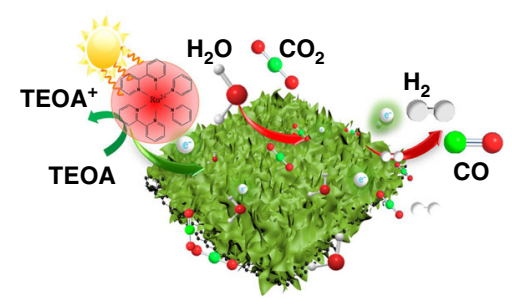

Fig. $4 \mathrm{CO}_{2}$ adsorption and photoelectrical properties of various photocatalysts. a $\mathrm{N}_{2}$ adsorption-desorption isotherms and $\mathbf{b} \mathrm{CO}_{2}$ adsorption isotherms of $\mathrm{GR}, \mathrm{Ni}(\mathrm{OH})_{2}, \mathrm{Ni}(\mathrm{OH})_{2} \mathrm{NPs}-10 \% \mathrm{GR}$ and $\mathrm{Ni}(\mathrm{OH})_{2}-10 \% \mathrm{GR}$. c Steady-state PL spectra and $\mathbf{d}$ time-resolved PL spectra decay of the photocatalytic $\mathrm{CO}{ }_{2}$ reduction systems with cocatalysts of $\mathrm{GR}, \mathrm{Ni}(\mathrm{OH})_{2}, \mathrm{Ni}(\mathrm{OH})_{2} \mathrm{NPs}-10 \% \mathrm{GR}, \mathrm{Ni}(\mathrm{OH})_{2}-10 \% \mathrm{GR}$ and without cocatalysts. e EIS Nyquist plots of $\mathrm{GR}, \mathrm{Ni}(\mathrm{OH})_{2}, \mathrm{Ni}$ $(\mathrm{OH})_{2} \mathrm{NPs}-10 \% \mathrm{GR}$, and $\mathrm{Ni}(\mathrm{OH})_{2}-10 \% \mathrm{GR}$. f Proposed photocatalytic mechanism of $\mathrm{Ni}(\mathrm{OH})_{2}-10 \% \mathrm{GR}$ with Ru photosensitizer for visible-light-driven photocatalytic $\mathrm{CO}_{2}$ reduction reaction.

counterparts, various complementary characterizations have been conducted. Firstly, the surface areas and $\mathrm{CO}_{2}$ uptake ability of these samples have been studied. As shown in Fig. $4 \mathrm{a}$ and Supplementary Table 3 , the BET surface area of $\mathrm{Ni}(\mathrm{OH})_{2}-10 \% \mathrm{GR}$ hybrid $\left(83 \mathrm{~m}^{2} \mathrm{~g}^{-1}\right)$ is obviously higher than that of blank $\mathrm{Ni}(\mathrm{OH})_{2}$ $\left(11 \mathrm{~m}^{2} \mathrm{~g}^{-1}\right)$ and $\mathrm{Ni}(\mathrm{OH})_{2}$ NPs-10\%GR composite $\left(40 \mathrm{~m}^{2} \mathrm{~g}^{-1}\right)$, which clearly indicates that introducing GR into the composite to constructe hierarchical nanosheet array structure is beneficial for increasing the specific surface area. The augmented surface area of $\mathrm{Ni}(\mathrm{OH})_{2}-10 \% \mathrm{GR}$ composite indicates an increased exposed surface active sites and effective mass transportation of reactants and products, which are conducive to enhance the photocatalytic activity of the composite ${ }^{17,23}$. In addition, the $\mathrm{CO}_{2}$ adsorption isotherms of $\mathrm{GR}, \mathrm{Ni}(\mathrm{OH})_{2}, \mathrm{Ni}(\mathrm{OH})_{2}-10 \% \mathrm{GR}$, and $\mathrm{Ni}(\mathrm{OH})_{2}$ NPs$10 \%$ GR composite have also been collected. As shown in Fig. $4 \mathrm{~b}$, it can be seen that GR has a strong adsorption capacity for $\mathrm{CO}_{2}$. After compositing $\mathrm{Ni}(\mathrm{OH})_{2}$ with $\mathrm{GR}, \mathrm{Ni}(\mathrm{OH})_{2}-10 \% \mathrm{GR}$ and $\mathrm{Ni}$ $(\mathrm{OH})_{2}$ NPs-10\%GR composites exhibit significantly improved $\mathrm{CO}_{2}$ adsorption capacity compared to that of blank $\mathrm{Ni}(\mathrm{OH})_{2}$. Notably, the $\mathrm{Ni}(\mathrm{OH})_{2}-10 \% \mathrm{GR}$ hybrid shows higher $\mathrm{CO}_{2}$ adsorption capacity than that of $\mathrm{Ni}(\mathrm{OH})_{2}$ NPs-10\%GR hybrid. Similar trends are also observed in $\mathrm{CO}_{2}$ temperature-programmed desorption (TPD) tests, as shown in Supplementary Fig. 22. These results suggest that the introduction of GR and construction of hierarchical nanosheet array structures can effectively enhance $\mathrm{CO}_{2}$ adsorption capacity of the composite, which is desirable to facilitate the enrichment and activation of $\mathrm{CO}_{2}$ molecule, thus contributing to the boosted photocatalytic performance of $\mathrm{Ni}(\mathrm{OH})_{2}-10 \% \mathrm{GR}$ composite for $\mathrm{CO}_{2}$ reduction ${ }^{12,44}$.

On the other hand, photoluminescence (PL) and electrochemical impedance spectroscopy (EIS) measurements have been conducted to explore the separation and transfer process of charge carriers, which are another crucial factor affecting the photoactivity of $\mathrm{CO}_{2}$ reduction ${ }^{7,44}$. As shown in Fig. $4 \mathrm{c}, \mathrm{d}$ and Supplementary Table 4, the cocatalysts contained systems show much lower PL intensities and shorter PL lifetimes than that of blank system. Generally, the lower PL emission intensity and shorter PL lifetime indicate the more efficient suppression of photoexcited charge recombination ${ }^{8,50}$. In addition, as shown in Supplementary Fig. 23, there is almost no influence on the light absorption of $\mathrm{Ru}$ by the addition of $\mathrm{Ni}(\mathrm{OH})_{2}-10 \% \mathrm{GR}$ cocatalyst, which further confirms that the quenching of PL intensity should be directly caused by the promoted transfer of photoexcited electrons ${ }^{51}$. Therefore, the introduction of 
cocatalysts can effectively promote the separation of charge carriers in the $\mathrm{CO}_{2}$ photoreduction system. Notably, compared with blank $\mathrm{Ni}(\mathrm{OH})_{2}$ and $\mathrm{Ni}(\mathrm{OH})_{2} \quad \mathrm{NPs}-10 \% \mathrm{GR}$ contained systems, $\mathrm{Ni}(\mathrm{OH})_{2}-10 \% \mathrm{GR}$ contained system exhibits significantly lower PL intensity and shorter PL lifetime, which validates that introduction of conductive GR into the composite for constructing hierarchical nanosheet array structures is able to effectively facilitate the separation of photogenerated charge carriers. In addition, as revealed in Fig. 4 e, the EIS spectrum of $\mathrm{Ni}(\mathrm{OH})_{2}-10 \%$ GR displays a smaller semicircle in the Nyquist plot than that of blank $\mathrm{Ni}(\mathrm{OH})_{2}$ and $\mathrm{Ni}(\mathrm{OH})_{2} \quad \mathrm{NPs}-10 \% \mathrm{GR}$ composite, which further confirms the elevated conductivity of the hybrid and the superiority of hierarchical nanosheet array structure in promoting the transfer of photogenerated charge carriers ${ }^{52,53}$.

Previously reported theoretical calculations indicate that $\mathrm{Ni}$ sites possess stronger $\mathrm{CO}_{2}$ adsorption affinity and weaker $\mathrm{H}^{+}$affinity than that of other transition metal sites $7,8,52$, which could be the main reason for the enhanced photocatalytic performance of $\mathrm{Ni}$ $(\mathrm{OH})_{2}-10 \% \mathrm{GR}$ composite compared to other transition metal hydroxide-GR composites $\left(\mathrm{Fe}(\mathrm{OH})_{3}-10 \% \mathrm{GR}, \mathrm{Cu}(\mathrm{OH})_{2}-10 \% \mathrm{GR}\right.$, and $\left.\mathrm{Co}(\mathrm{OH})_{2}-10 \% \mathrm{GR}\right)$. As shown in Supplementary Fig. 24a, b, the enhanced $\mathrm{CO}_{2}$ adsorption capacity of $\mathrm{Ni}(\mathrm{OH})_{2}-10 \% \mathrm{GR}$ composite is confirmed by $\mathrm{CO}_{2}$ adsorption isotherm and $\mathrm{CO}_{2}$ TPD test. Notably, the $\mathrm{Co}(\mathrm{OH})_{2}-10 \% \mathrm{GR}$ composite shows the most effective charge separation and transfer among these samples as reflected by EIS and PL spectra analysis (Supplementary Fig. 24c-e and Supplementary Table 5). However, because of the lowest $\mathrm{CO}_{2}$ adsorption capacity of $\mathrm{Co}(\mathrm{OH})_{2}-10 \% \mathrm{GR}$ composite (Supplementary Fig. 24a, b), its photocatalytic performance is inferior in diluted $\mathrm{CO}_{2}$, which further confirms that $\mathrm{CO}_{2}$ adsorption capacity is the crucial factor for affecting the photocatalytic performance of the catalysts.

The Mott-Schottky measurements in Supplementary Fig. 25a-c show that flat band potentials of $\mathrm{Ni}(\mathrm{OH})_{2}, \mathrm{GR}, \mathrm{Ni}(\mathrm{OH})_{2}-10 \% \mathrm{GR}$ are ca. $-0.7 \mathrm{~V},-0.82 \mathrm{~V}$ and $-0.76 \mathrm{~V}$ vs. normal hydrogen electrode (NHE), which are lower than that of $\mathrm{E}\left(\mathrm{Ru}(\mathrm{bpy})_{3}{ }^{2+*} / \mathrm{Ru}\right.$ $\left.(\text { bpy })_{3}{ }^{+}\right)=-1.09 \mathrm{~V}$ (vs. NHE) and higher than the redox potential of $\mathrm{E}\left(\mathrm{CO}_{2} / \mathrm{CO}\right)=-0.53 \mathrm{~V}$ (vs. NHE) ${ }^{54,55}$. Hence, $\mathrm{Ni}$ $(\mathrm{OH})_{2}, \mathrm{GR}$ and $\mathrm{Ni}(\mathrm{OH})_{2}-10 \% \mathrm{GR}$ all have suitable redox potential and can receive electrons from the reduced $\mathrm{Ru}$ complex to drive the photocatalytic $\mathrm{CO}_{2}$-to- $\mathrm{CO}$ reduction reaction. In addition, the energy level diagram illustrated in Supplementary Fig. 25d indicates that the fermi level $\left(\mathrm{E}_{\mathrm{F}}\right)$ value of $\mathrm{GR}$ is lower than the lowest unoccupied molecular orbital (LUMO) value of $\left[\mathrm{Ru}(\mathrm{bpy})_{3}\right]$ $\mathrm{Cl}_{2}$ and higher than the $\mathrm{E}_{\mathrm{F}}$ value of $\mathrm{Ni}(\mathrm{OH})_{2}$ (Supplementary Note 12). Therefore, the high carrier mobility and well-aligned energy levels of GR enable it to efficiently facilitate electron transfer from photosensitizers to $\mathrm{Ni}(\mathrm{OH})_{2}{ }^{51,56}$. On the basis of the above analysis, a possible reaction mechanism for the $\mathrm{CO}_{2}$ photoreduction over $\mathrm{Ni}(\mathrm{OH})_{2}-10 \% \mathrm{GR}$ composite has been proposed. As shown in Fig. 4f, under visible-light irradiation, the $\left[\mathrm{Ru}(\mathrm{bpy})_{3}\right]^{2+}$ photosensitizer is activated to the excited state $\left[\mathrm{Ru}(\mathrm{bpy})_{3}\right]^{2+*}$, which is then reductively quenched by TEOA, forming the reduced photosensitizer $\left[\mathrm{Ru}(\mathrm{bpy})_{3}\right]^{+44}$. Meanwhile, TEOA is oxidized to diethanolamine and glycolaldehyde ${ }^{57,58}$. Subsequently, the reduced photosensitizer $\left[\mathrm{Ru}(\mathrm{bpy})_{3}\right]^{+}$transfers electrons to GR, which further relays the electron to $\mathrm{Ni}(\mathrm{OH})_{2}$. Finally, the adsorbed $\mathrm{CO}_{2}$ on the $\mathrm{Ni}(\mathrm{OH})_{2}$ surface are activated and reduced to $\mathrm{CO}$. At the same time, parts of excited electrons are accepted by protons to produce $\mathrm{H}_{2}{ }^{7,55}$. The strong $\mathrm{CO}_{2}$ affinity and weak $\mathrm{H}^{+}$affinity of $\mathrm{Ni}$ sites endow $\mathrm{Ni}(\mathrm{OH})_{2}$ with great potential for $\mathrm{CO}_{2}$ uptake, thus promoting $\mathrm{CO}_{2}$-to- $\mathrm{CO}$ conversion and inhibiting the generation of $\mathrm{H}_{2}$ byproduct. In addition, compositing $\mathrm{Ni}(\mathrm{OH})_{2}$ with $\mathrm{GR}$ to construct hierarchical nanosheet array structures can synergistically expose abundant active sites for photocatalytic $\mathrm{CO}_{2}$ reduction, improve
$\mathrm{CO}_{2}$ adsorption and promote separation and transfer of charge carriers. Therefore, $\mathrm{Ni}(\mathrm{OH})_{2}-10 \% \mathrm{GR}$ composite displays the optimal photocatalytic $\mathrm{CO}_{2}$ reduction performance as compared to that of other counterparts, including bare $\mathrm{Ni}(\mathrm{OH})_{2}, \mathrm{Ni}(\mathrm{OH})_{2}$ NPs-GR, $\mathrm{Fe}(\mathrm{OH})_{3}-\mathrm{GR}, \mathrm{Cu}(\mathrm{OH})_{2}-\mathrm{GR}$ and $\mathrm{Co}(\mathrm{OH})_{2}-\mathrm{GR}$.

\section{Discussion}

In summary, we have rationally synthesized a series of transition metal hydroxides, including $\mathrm{Ni}(\mathrm{OH})_{2}, \mathrm{Fe}(\mathrm{OH})_{3}, \mathrm{Cu}(\mathrm{OH})_{2}$, and $\mathrm{Co}(\mathrm{OH})_{2}$, on the GR platform to act as cocatalysts for artificial photoreduction of $\mathrm{CO}_{2}$. Specifically, hierarchical $\mathrm{Ni}(\mathrm{OH})_{2}$ nanosheet arrays-graphene $\left(\mathrm{Ni}(\mathrm{OH})_{2}-\mathrm{GR}\right)$ composites exhibit superior photocatalytic activity and selectivity. With the Ru-dye visible-light photosensitizer, the optimal $\mathrm{Ni}(\mathrm{OH})_{2}-10 \% \mathrm{GR}$ composite exhibits a $\mathrm{CO}$ formation rate of $10725 \mu \mathrm{mol} \mathrm{h}^{-1} \mathrm{~g}^{-1}$ with selectivity of $96 \%$. Even in the diluted $\mathrm{CO}_{2}, \mathrm{Ni}(\mathrm{OH})_{2}-10 \% \mathrm{GR}$ composite still exhibits excellent photoactivity with the $\mathrm{CO}$ generation rate of $7432 \mu \mathrm{mol} \mathrm{h}{ }^{-1} \mathrm{~g}^{-1}$ and high selectivity of $92 \%$, which is markedly higher than that of other counterparts. A series of complementary characterizations suggest that the synergy of enhanced $\mathrm{CO}_{2}$ adsorption capacity, increased surface active sites, and improved charge separation/transfer of $\mathrm{Ni}(\mathrm{OH})_{2}-10 \% \mathrm{GR}$ composite leads to its boosted optimal performance for photocatalytic $\mathrm{CO}_{2}$ reduction as compared to that of other counterparts. It is expected that our current work could exploit new frontiers for the rational construction of earth-abundant transition metal hydroxides-based cocatalysts on graphene and other $2 \mathrm{D}$ material platforms for efficient and selective photoreduction of $\mathrm{CO}_{2}$ to value-added chemical feedstocks.

\section{Methods}

Materials. Hydrochloric acid $(\mathrm{HCl})$, nickel nitrate hexahydrate $(\mathrm{Ni}$ $\left.\left(\mathrm{NO}_{3}\right)_{2} \cdot 6 \mathrm{H}_{2} \mathrm{O}\right)$, triethanolamine $\left(\mathrm{C}_{6} \mathrm{H}_{15} \mathrm{O}_{3} \mathrm{~N}\right.$, TEOA), sulfuric acid $\left(\mathrm{H}_{2} \mathrm{SO}_{4}\right)$, cobalt nitrate hexahydrate $\left(\mathrm{Co}\left(\mathrm{NO}_{3}\right)_{2} \cdot 6 \mathrm{H}_{2} \mathrm{O}\right)$, acetonitrile $\left(\mathrm{CH}_{3} \mathrm{CN}, \mathrm{MeCN}\right)$ deuterium oxide $\left(\mathrm{D}_{2} \mathrm{O}\right)$, copper nitrate trihydrate $\left(\mathrm{Cu}\left(\mathrm{NO}_{3}\right)_{2} \cdot 3 \mathrm{H}_{2} \mathrm{O}\right)$, hexamethylenetetramine $\left(\mathrm{C}_{6} \mathrm{H}_{12} \mathrm{~N}_{4}\right.$, HMTA), hydrogen peroxide $\left(\mathrm{H}_{2} \mathrm{O}_{2}\right)$, iron nitrate nonahydrate $\left(\mathrm{Fe}\left(\mathrm{NO}_{3}\right)_{3} \cdot 9 \mathrm{H}_{2} \mathrm{O}\right)$, potassium permanganate $\left(\mathrm{KMnO}_{4}\right)$, trisodium citrate $\left(\mathrm{C}_{6} \mathrm{H}_{5} \mathrm{O}_{7} \mathrm{Na}_{3}\right)$ and urea $\left(\mathrm{CH}_{4} \mathrm{~N}_{2} \mathrm{O}\right)$ were supplied by Sinopharm Chemical Reagent Co., Ltd. (Shanghai, China). Cis-Dichlorobis(2,2-bipyridine)ruthenium (II) $\left(\left[\mathrm{Ru}(\mathrm{bpy})_{2}\right] \mathrm{Cl}_{2}\right)$ were purchased form Sigma-Aldrich Co., Ltd (Shanghai, China). All chemicals were analytical grade and used as received. Deionized (DI) water was obtained from local sources.

Catalyst preparation. Synthesis of graphene oxide: GO was synthesized by a modified Hummers' method ${ }^{34,59-62}$. In detail, $10 \mathrm{~g}$ graphite powder (supplied from Qingdao Zhongtian Company, China) was put into $230 \mathrm{~mL}$ concentrated $\mathrm{H}_{2} \mathrm{SO}_{4}$ under moderate stirring. Then, $30 \mathrm{~g} \mathrm{KMnO}_{4}$ was added gradually under stirring and the solution was cold below $5{ }^{\circ} \mathrm{C}$ in an ice bath. After that, the solution was heated to $35^{\circ} \mathrm{C}$ in a water-bath and kept stirring for $2 \mathrm{~h}$. Then, the mixture was diluted with $500 \mathrm{~mL}$ DI water in an ice bath to keep the temperature below $5^{\circ} \mathrm{C}$ Shortly after the further diluted with $1.5 \mathrm{~L}$ of DI water, $80 \mathrm{~mL} 30 \% \mathrm{H}_{2} \mathrm{O}_{2}$ was then added into the mixture. The mixture was centrifuged and washed with $1: 10 \mathrm{HCl}$ aqueous solution to remove metal ions followed by DI water to remove the acid. After that, the mixture was dialyzed for one week and the final GO sample was obtained after full sonication.

Synthesis of nickel hydroxide nanosheet arrays-graphene $\left(\mathrm{Ni}(\mathrm{OH})_{2}-\mathrm{GR}\right)$ composites: firstly, a certain amount of GO was dispersed into $50 \mathrm{~mL}$ DI water with ultrasonication for $1 \mathrm{~h}$. Then, $2.5 \mathrm{mmol} \mathrm{Ni}\left(\mathrm{NO}_{3}\right)_{2} \cdot 6 \mathrm{H}_{2} \mathrm{O}$ was dissolved into the GO solution and stirred for $0.5 \mathrm{~h}$. Afterward, a $50 \mathrm{~mL}$ solution containing $0.25 \mathrm{mmol}$ of $\mathrm{C}_{6} \mathrm{H}_{5} \mathrm{O}_{7} \mathrm{Na}_{3}$ and $2.5 \mathrm{mmol}$ of HMTA was incorporated to the above-mixed solution and stirred for $1 \mathrm{~h}$. After that, the obtained solution was heated to $363 \mathrm{~K}$ and maintained for $10 \mathrm{~h}$ with vigorous agitation. Subsequently, when the solution temperature was cooled to $298 \mathrm{~K}$, the sample was collected by centrifugation and washed thoroughly with DI water. After finally treated by freeze-drying, $\mathrm{Ni}(\mathrm{OH})_{2}$ GR composites with different contents of GR $(1,5,10,30$, and $50 \mathrm{wt} \%)$ were obtained. Other transition metal hydroxide-graphene composites $\left(\mathrm{Co}(\mathrm{OH})_{2}-\mathrm{GR}\right.$, $\mathrm{Fe}(\mathrm{OH})_{3}-\mathrm{GR}$ and $\left.\mathrm{Cu}(\mathrm{OH})_{2}-\mathrm{GR}\right)$ were prepared according to the same protocol as that for $\mathrm{Ni}(\mathrm{OH})_{2}-\mathrm{GR}$ composite except for using the same amount of the corresponding transition metal nitrate instead. In comparison, blank $\mathrm{Ni}(\mathrm{OH})_{2}, \mathrm{Co}$ $(\mathrm{OH})_{2}, \mathrm{Fe}(\mathrm{OH})_{3}$, and $\mathrm{Cu}(\mathrm{OH})_{2}$ were prepared using the identical process without GR platform. In addition, bare GR was prepared using the same method in the absence of transition metal nitrate. 


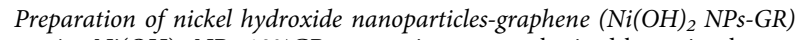
composite: $\mathrm{Ni}(\mathrm{OH})_{2} \mathrm{NPs}-10 \% \mathrm{GR}$ composite was synthesized by a simple hydrothermal method ${ }^{18,63}$. Typically, $2 \mathrm{mmol} \mathrm{Ni}\left(\mathrm{NO}_{3}\right)_{2} \cdot 6 \mathrm{H}_{2} \mathrm{O}, 6 \mathrm{mg} \mathrm{GO}$ and $250 \mathrm{mg}$ of urea were dispersed into $30 \mathrm{~mL}$ DI water with ultrasonication for $1 \mathrm{~h}$. After that, the mixed solution was added into a $50 \mathrm{~mL}$ Teflon-lined autoclave. The hydrothermal treatment was performed at $363 \mathrm{~K}$ for $10 \mathrm{~h}$. When the temperature of solution was reduced to $298 \mathrm{~K}$, the product was gathered by centrifugation, washed thoroughly with DI water, and treated by freeze-drying.

Characterization. The structures of the samples were determined by dual beam SEM (Helios G4 CX) and TEM (FEI Tecnai G2 F20). AFM measurements were performed in Agilent 5500 AFM (Agilent Technologies, USA). XRD patterns were collected on a Rigaku Miniflex diffractometer with $\mathrm{Cu} \mathrm{Ka}$ radiation. Thermogravimetric (TG) analysis was carried out on a PerkinElmer TGA7 analyzer under air atmosphere. BET surface areas and $\mathrm{CO}_{2}$ adsorption capacity of the as-prepared samples were evaluated by Micromeritics TriStar II PLUS 3020 equipment at 77 and $298 \mathrm{~K}$, respectively. $\mathrm{CO}_{2}$ TPD measurements were performed on Micromeritics Auto Chem II 2920 instrument. XPS tests were executed on Thermo Scientific Escalab 250Xi spectrometer. Raman spectra were tested on a Renishaw inVia Raman System 1000 with a $532 \mathrm{~nm}$ Nd:YAG excitation source. Zeta-potentials ( $\zeta)$ test was performed on Zetasizer $3000 \mathrm{HSA} .{ }^{1} \mathrm{H}$ nuclear magnetic resonance $\left({ }^{1} \mathrm{H}\right.$ NMR) measurement was conducted on Bruker DPX 400 spectrometer. Steady-state PL spectra and PL lifetime of these samples were tested on Edinburgh FLS-920 spectrofluorometer. The above PL measurements were performed in $\mathrm{MeCN} / \mathrm{H}_{2} \mathrm{O}$ / TEOA (3:2:1, $6 \mathrm{~mL})$ mixed solution containing $7.5 \mathrm{mg} \mathrm{Ru}$-dye and $1 \mathrm{mg}$ asprepared cocatalysts. The excitation wavelength was $405 \mathrm{~nm}$ when steady-state PL was measured. For the test of PL lifetime, the light source was $405 \mathrm{~nm}$ laser and the emission wavelength was $630 \mathrm{~nm}$. EIS and Mott-Schottky measurements were implemented on electrochemical workstation (Autolab PGSTAT204).

Photocatalytic $\mathrm{CO}_{2}$ reduction testing. $\mathrm{MeCN} / \mathrm{H}_{2} \mathrm{O} / \mathrm{TEOA}(3: 2: 1,6 \mathrm{~mL})$ mixed solution containing $7.5 \mathrm{mg}\left[\mathrm{Ru}\right.$ (bpy) $\left.{ }_{3}\right] \mathrm{Cl}_{2} \cdot 6 \mathrm{H}_{2} \mathrm{O}$ photosensitizer and $1 \mathrm{mg}$ asprepared cocatalysts was added into a gas-closed quartz reactor. Then, the quartz reactor was purged with $\mathrm{CO}_{2}(99.9999 \%$ or $10 \%)$ for $30 \mathrm{~min}$. A $300 \mathrm{~W}$ Xe lamp (PLS-SXE300D, Perfectlight) with UV cutoff filter $(\lambda \geq 420 \mathrm{~nm})$ was applied to as the light source and the light intensity was measured to be $405 \mathrm{~mW} \mathrm{~cm}^{-2}$. The reactor temperature was hold at room temperature by an electronic fan. For each $2 \mathrm{~h}$, the gaseous products were analysed by gas chromatography (GC 2014C, Shimadzu). $\mathrm{H}_{2}$ was analyzed by a thermal conductivity detector (TCD). $\mathrm{CO}$ was converted to $\mathrm{CH}_{4}$ using a methanation reactor and then detected by a flame ionization detector (FID). The liquid products were analysed using ${ }^{1} \mathrm{H}$ NMR. Isotope test was conducted by gas chromatography-mass spectrometry (GC-MS, 7890B and $5977 \mathrm{~A}$, Agilent). The AQE was calculated according to the equation: $\mathrm{AQE}=[(2 \times$ number of $\mathrm{CO}$ evolved molecules $) /($ number of incident photons $)] \times$ $100 \%$. The turnover number (TON) for CO over Ru atoms was calculated using the following equation: $\mathrm{TON}=$ moles of $\mathrm{CO}$ evolved/moles of $\mathrm{Ru}$ atoms on photocatalyst. For recycling tests, the sample was collected and rinsed with DI water three times after $2 \mathrm{~h}$ of photocatalytic reaction. Then, the fresh reaction solution containing $7.5 \mathrm{mg} \mathrm{Ru}$-dye was mixed with the used cocatalysts to conduct the second cycle experiment. By analogy, the subsequent four recycling tests were conducted.

\section{Data availability}

The data that support the findings of this study are available from the corresponding author on request. Source data are provided with this paper.

Received: 30 March 2020; Accepted: 11 September 2020;

Published online: 14 October 2020

\section{References}

1. Zhang, N. et al. Waltzing with the versatile platform of graphene to synthesize composite photocatalysts. Chem. Rev. 115, 10307-10377 (2015).

2. $\mathrm{Li}$, X. et al. Cocatalysts for selective photoreduction of $\mathrm{CO}_{2}$ into solar fuels. Chem. Rev. 119, 3962-4179 (2019).

3. Collado, L. et al. Unravelling the effect of charge dynamics at the plasmonic metal/semiconductor interface for $\mathrm{CO}_{2}$ photoreduction. Nat. Commun. $\mathbf{9}$, 1-10 (2018).

4. Wang, $\mathrm{S}$. et al. Porous hypercrosslinked polymer- $\mathrm{TiO}_{2}$-graphene composite photocatalysts for visible-light-driven $\mathrm{CO}_{2}$ conversion. Nat. Commun. 10, 676 (2019).

5. Li, K., Peng, B. \& Peng, T. Recent advances in heterogeneous photocatalytic $\mathrm{CO}_{2}$ conversion to solar fuels. ACS Catal. 6, 7485-7527 (2016).

6. Dong, C. et al. Size-dependent activity and selectivity of carbon dioxide photocatalytic reduction over platinum nanoparticles. Nat. Commun. 9, 1252 (2018).
7. Han, B. et al. Nickel metal-organic framework monolayers for photoreduction of diluted $\mathrm{CO}_{2}$ : metal-node-dependent activity and selectivity. Angew. Chem. Int. Ed. 57, 16811-16815 (2018).

8. Zhong, W. et al. A covalent organic framework bearing single Ni sites as a synergistic photocatalyst for selective photoreduction of $\mathrm{CO}_{2}$ to CO. J. Am. Chem. Soc. 141, 7615-7621 (2019).

9. Niu, $\mathrm{K}$. et al. A spongy nickel-organic $\mathrm{CO}_{2}$ reduction photocatalyst for nearly 100\% selective CO production. Sci. Adv. 3, e1700921 (2017).

10. Chen, S. et al. Surface strategies for particulate photocatalysts toward artificial photosynthesis. Joule 2, 2260-2288 (2018).

11. Chang, X., Wang, T. \& Gong, J. $\mathrm{CO}_{2}$ photo-reduction: insights into $\mathrm{CO}_{2}$ activation and reaction on surfaces of photocatalysts. Energy Environ. Sci. 9, 2177-2196 (2016).

12. Wang, S., Guan, B. Y. \& Lou, X. W. Rationally designed hierarchical N-doped carbon@ $\mathrm{NiCo}_{2} \mathrm{O}_{4}$ double-shelled nanoboxes for enhanced visible light $\mathrm{CO}_{2}$ reduction. Energy Environ. Sci. 11, 306-310 (2018).

13. Lin, X. et al. Magnetic hollow spheres assembled from graphene-encapsulated nickel nanoparticles for efficient photocatalytic $\mathrm{CO}_{2}$ reduction. ACS Appl. Energy Mater 2, 7670-7678 (2019).

14. Ferrando, R., Jellinek, J. \& Johnston, R. L. Nanoalloys: from theory to applications of alloy clusters and nanoparticles. Chem. Rev. 108, 845-910 (2008).

15. Vasileff, A. et al. Surface and interface engineering in copper-based bimetallic materials for selective $\mathrm{CO}_{2}$ electroreduction. Chem. 4, 1809-1831 (2018).

16. Xiong, J. et al. Ultrathin structured photocatalysts: a versatile platform for $\mathrm{CO}_{2}$ reduction. Appl. Catal. B 256, 117788 (2019).

17. Meng, A. et al. Hierarchical $\mathrm{TiO}_{2} / \mathrm{Ni}(\mathrm{OH})_{2}$ composite fibers with enhanced photocatalytic $\mathrm{CO}_{2}$ reduction performance. J. Mater. Chem. A 6, 4729-4736 (2018).

18. Tang, T. et al. Kinetically controlled coprecipitation for general fast synthesis of sandwiched metal hydroxide nanosheets/graphene composites toward efficient water splitting. Adv. Funct. Mater. 28, 1704594 (2018).

19. Grote, F. et al. Self-stacked reduced graphene oxide nanosheets coated with cobalt-nickel hydroxide by one-step electrochemical deposition toward flexible electrochromic supercapacitors. Small 11, 4666-4672 (2015).

20. Yang, M.-Q. et al. Artificial photosynthesis over graphene-semiconductor composites. Are we getting better? Chem. Soc. Rev. 43, 8240-8254 (2014).

21. Yang, M.-Q. \& Xu, Y.-J. Photocatalytic conversion of $\mathrm{CO}_{2}$ over graphenebased composites: current status and future perspective. Nanoscale Horiz. 1, 185-200 (2016).

22. Ong, W.-J. et al. Graphene oxide as a structure-directing agent for the twodimensional interface engineering of sandwich-like graphene-g- $\mathrm{C}_{3} \mathrm{~N}_{4}$ hybrid nanostructures with enhanced visible-light photoreduction of $\mathrm{CO}_{2}$ to methane. Chem. Commun. 51, 858-861 (2015).

23. Yang, M.-Q. et al. Ultrathin nickel boron oxide nanosheets assembled vertically on graphene: a new hybrid $2 \mathrm{D}$ material for enhanced photo/electrocatalysis. Mater. Horiz. 4, 885-894 (2017)

24. Ma, Y. et al. Homogeneous metal nitrate hydroxide nanoarrays grown on nickel foam for efficient electrocatalytic oxygen evolution. Small 14, 1803783 (2018).

25. Sun, Z. et al. Catalysis of carbon dioxide photoreduction on nanosheets: fundamentals and challenges. Angew. Chem. Int. Ed. 57, 7610-7627 (2018).

26. Hou, W., Xiao, Y. \& Han, G. An interconnected ternary $\mathrm{MIn}_{2} \mathrm{~S}_{4}(\mathrm{M}=\mathrm{Fe}, \mathrm{Co}$, $\mathrm{Ni}$ ) thiospinel nanosheet array: a type of efficient platinum-free counter electrode for dye-sensitized solar cells. Angew. Chem. Int. Ed. 56, 9146-9150 (2017).

27. Kim, D. et al. Synergistic geometric and electronic effects for electrochemical reduction of carbon dioxide using gold-copper bimetallic nanoparticles. Nat. Commun. 5, 4948 (2014).

28. Nagaraju, G., Cha, S. M. \& Yu, J. S. Ultrathin nickel hydroxide nanosheet arrays grafted biomass-derived honeycomb-like porous carbon with improved electrochemical performance as a supercapacitive material. Sci. Rep. 7, 45201 (2017).

29. Lin, H. \& Wang, X. Epitaxy of radial high-energy-facetted ultrathin $\mathrm{TiO}_{2}$ nanosheets onto nanowires for enhanced photoreactivities. Adv. Funct. Mater. 26, 1580-1589 (2016)

30. Wei, G. et al. Carbon quantum dot-induced self-assembly of ultrathin $\mathrm{Ni}$ $(\mathrm{OH})_{2}$ nanosheets: a facile method for fabricating three-dimensional porous hierarchical composite micro-nanostructures with excellent supercapacitor performance. Nano Res. 10, 3005-3017 (2017).

31. Fan, H. et al. Controllable synthesis of ultrathin transition-metal hydroxide nanosheets and their extended composite nanostructures for enhanced catalytic activity in the heck reaction. Angew. Chem. Int. Ed. 55, 2167-2170 (2016).

32. Hussain, N. et al. Ultrathin mesoporous F-doped $\alpha-\mathrm{Ni}(\mathrm{OH})_{2}$ nanosheets as an efficient electrode material for water splitting and supercapacitors. J. Mater. Chem. A 7, 9656-9664 (2019).

33. Lee, J. W., Ko, J. M. \& Kim, J.-D. Hierarchical microspheres based on $\alpha-\mathrm{Ni}$ $(\mathrm{OH})_{2}$ nanosheets intercalated with different anions: synthesis, anion 
exchange, and effect of intercalated anions on electrochemical capacitance. J. Phys. Chem. C 115, 19445-19454 (2011).

34. Lu, K.-Q. et al. Rational utilization of highly conductive, commercial elicarb graphene to advance the graphene-semiconductor composite photocatalysis. Appl. Catal. B 224, 424-432 (2018).

35. Jia, D. et al. Hierarchical $\alpha-\mathrm{Ni}(\mathrm{OH}) 2$ composed of ultrathin nanosheets with controlled interlayer distances and their enhanced catalytic performance. ACS Appl. Mater. Interfaces 9, 20476-20483 (2017).

36. Li, Y. et al. Effective catalytic reduction of 4-nitrophenol to 4-aminophenol over etched halloysite nanotubes@a-Ni(OH)2. ACS Appl. Energy Mater. 3, $4756-4766$ (2020)

37. Xie, J. et al. Copper-incorporated hierarchical wire-on-sheet $\alpha-\mathrm{Ni}(\mathrm{OH})_{2}$ nanoarrays as robust trifunctional catalysts for synergistic hydrogen generation and urea oxidation. J. Mater. Chem. A 7, 13577-13584 (2019)

38. Bag, S. \& Raj, C. R. Layered inorganic-organic hybrid material based on reduced graphene oxide and $\alpha-\mathrm{Ni}(\mathrm{OH})_{2}$ for high performance supercapacitor electrodes. J. Mater. Chem. A 2, 17848-17856 (2014).

39. Weng, B. et al. Toward the enhanced photoactivity and photostability of $\mathrm{ZnO}$ nanospheres via intimate surface coating with reduced graphene oxide. J. Mater. Chem. A 2, 9380-9389 (2014).

40. Lu, K.-Q. et al. Insight into the origin of boosted photosensitive efficiency of graphene from the cooperative experiment and theory study. J. Phys. Chem. C 120, 27091-27103 (2016)

41. Ke, Q. et al.3D TiO ${ }_{2} @ \mathrm{Ni}(\mathrm{OH})_{2}$ core-shell arrays with tunable nanostructure for hybrid supercapacitor application. Sci. Rep. 5, 13940 (2015).

42. Wang, $\mathrm{H}$. et al. $\mathrm{Ni}(\mathrm{OH})_{2}$ nanoplates grown on graphene as advanced electrochemical pseudocapacitor materials. J. Am. Chem. Soc. 132, 7472-7477 (2010).

43. Ouyang, T. et al. A dinuclear cobalt cryptate as a homogeneous photocatalyst for highly selective and efficient visible-light driven $\mathrm{CO}_{2}$ reduction to $\mathrm{CO}$ in $\mathrm{CN}_{3} \mathrm{CN} / \mathrm{H}_{2} \mathrm{O}$ solution. Angew. Chem. Int. Ed. 56, 738-743 (2017).

44. Wang, Y., Wang, S. \& Lou, X. W. Dispersed nickel cobalt oxyphosphide nanoparticles confined in multichannel hollow carbon fibers for photocatalytic $\mathrm{CO}_{2}$ reduction. Angew. Chem. Int. Ed. 58, 17236-17240 (2019).

45. Liu, W. et al. A scalable general synthetic approach toward ultrathin iminelinked two-dimensional covalent organic framework nanosheets for photocatalytic $\mathrm{CO}_{2}$ reduction. J. Am. Chem. Soc. 141, 17431-17440 (2019).

46. Wu, L. Y. et al. Encapsulating perovskite quantum dots in iron-based metalorganic frameworks (MOFs) for efficient photocatalytic $\mathrm{CO}_{2}$ reduction. Angew. Chem. Int. Ed. 58, 9491-9495 (2019).

47. Li, A. et al. Three-phase photocatalysis for the enhanced selectivity and activity of $\mathrm{CO}_{2}$ reduction on a hydrophobic surface. Angew. Chem. Int. Ed. 58, 14549-14555 (2019).

48. Tamaki, Y. \& Ishitani, O. Supramolecular photocatalysts for the reduction of $\mathrm{CO}_{2}$. ACS Catal. 7, 3394-3409 (2017).

49. Kimura, E. et al. New series of multifunctionalized nickel (II)-cyclam (cyclam $=1,4,8,11$-tetraazacyclotetradecane) complexes. Application to the photoreduction of carbon dioxide. Inorg. Chem. 33, 770-778 (1994).

50. Zhu, W. et al. Selective reduction of $\mathrm{CO}_{2}$ by conductive MOF nanosheets as an efficient co-catalyst under visible light illumination. Appl. Catal. B 238, 339-345 (2018).

51. Gao, C. et al. Heterogeneous single-atom catalyst for visible-light-driven highturnover $\mathrm{CO}_{2}$ reduction: the role of electron transfer. Adv. Mater. 30, 1704624 (2018).

52. Wang, X.-K. et al. Monometallic catalytic models hosted in stable metal-organic frameworks for tunable $\mathrm{CO}_{2}$ photoreduction. ACS Catal. 9, 1726-1732 (2019).

53. Weng, B. et al. Stabilizing ultrasmall Au clusters for enhanced photoredox catalysis. Nat. Commun. 9, 1-11 (2018).

54. Schneider, J. et al. Thermodynamics and kinetics of $\mathrm{CO}_{2}, \mathrm{CO}$, and $\mathrm{H}^{+}$binding to the metal centre of $\mathrm{CO}_{2}$ reductioncatalysts. Chem. Soc. Rev. 41, 2036-2051 (2012).

55. Han, B. et al. Hierarchical $\mathrm{NiCo}_{2} \mathrm{O}_{4}$ hollow nanocages for photoreduction of diluted $\mathrm{CO}_{2}$ : Adsorption and active sites engineering. Appl. Catal. B 260, 118208 (2020)

56. $\mathrm{Mu}$, Q. et al. Electrostatic charge transfer for boosting the photocatalytic $\mathrm{CO}_{2}$ reduction on metal centers of $2 \mathrm{D} \mathrm{MOF} / \mathrm{rGO}$ heterostructure. Appl. Catal. $B$ 262, 118144 (2020).

57. Zhu, Y. et al. Bimetallic Ag-Cu supported on graphitic carbon nitride nanotubes for improved visible-light photocatalytic hydrogen production. ACS Appl. Mater. Interfaces 10, 9468-9477 (2018).
58. Du, P. et al. Photocatalytic generation of hydrogen from water using a platinum (II) terpyridyl acetylide chromophore. J. Am. Chem. Soc. 128, 7726-7727 (2006)

59. Zhang, Y. et al. Engineering the unique 2D mat of graphene to achieve graphene- $\mathrm{TiO}_{2}$ nanocomposite for photocatalytic selective transformation: what advantage does graphene have over its forebear carbon nanotube? ACS Nano 5, 7426-7435 (2011).

60. Zhang, Y. et al. Graphene transforms wide band gap $\mathrm{ZnS}$ to a visible light photocatalyst. The new role of graphene as a macromolecular photosensitizer ACS Nano 6, 9777-9789 (2012).

61. Zhang, N. et al. Toward improving the graphene-semiconductor composite photoactivity via the addition of metal ions as generic interfacial mediator. ACS Nano 8, 623-633 (2013).

62. Hummers, W. S. Jr. \& Offeman, R. E. Preparation of graphitic oxide. J. Am. Chem. Soc. 80, 1339-1339 (1958).

63. Chen, $\mathrm{X}$ et al. One-pot hydrothermal synthesis of reduced graphene oxide/ carbon nanotube/ $\alpha-\mathrm{Ni}(\mathrm{OH}) 2$ composites for high performance electrochemical supercapacitor. J. Power Sour. 243, 555-561 (2013).

\section{Acknowledgements}

Y.-J.X. acknowledges the support from the NSFC (21872029, U1463204, 20903023, 21173045 and 22072023), the Award Program for Minjiang Scholar Professorship, the Independent Research Project of State Key Laboratory of Photocatalysis on Energy and Environment (NO. 2014A05), the Program for Leading Talents of Fujian Universities, the 1st Program of Fujian Province for Top Creative Young Talents, and the NSF of Fujian Province (2017J07002, 2019J0106).

\section{Author contributions}

Y.-J.X. proposed the research direction and supervised the project. K.Q.L. designed and preformed the experiments. Y.H.L. and F.Z. performed XRD measurement and analysis. M.Y.Q. and X.C. carried out SEM characterization and analysis. Y.-J.X. and K.Q.L. wrote and revised the manuscript. Z.-R.T., Y.M.A.Y., M.A., and M.C. provided helpful suggestions. All authors participated in discussion and reviewed the paper before submission.

\section{Competing interests}

The authors declare no competing interests.

\section{Additional information}

Supplementary information is available for this paper at https://doi.org/10.1038/s41467020-18944-1.

Correspondence and requests for materials should be addressed to Y.-J.X.

Peer review information Nature Communications thanks Hermenegildo Garcia and other, anonymous, reviewers for their contributions to the peer review of this work.

Reprints and permission information is available at http://www.nature.com/reprints

Publisher's note Springer Nature remains neutral with regard to jurisdictional claims in published maps and institutional affiliations.

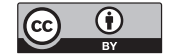

Open Access This article is licensed under a Creative Commons Attribution 4.0 International License, which permits use, sharing, adaptation, distribution and reproduction in any medium or format, as long as you give appropriate credit to the original author(s) and the source, provide a link to the Creative Commons license, and indicate if changes were made. The images or other third party material in this article are included in the article's Creative Commons license, unless indicated otherwise in a credit line to the material. If material is not included in the article's Creative Commons license and your intended use is not permitted by statutory regulation or exceeds the permitted use, you will need to obtain permission directly from the copyright holder. To view a copy of this license, visit http://creativecommons.org/ licenses/by/4.0/.

(C) The Author(s) 2020 